\title{
FOR THE RECORD
}

\section{The protein phosphatase 2C (PP2C) superfamily: Detection of bacterial homologues}

\author{
PEER BORK, NIGEL P. BROWN, HEDVIG HEGYI, AND JÖRG SCHULTZ \\ European Molecular Biology Laboratory, Heidelberg, and Max-Delbrück-Center for Molecular Medicine, \\ Berlin-Buch, Germany
}

(ReCEIved February 14, 1996; ACCEPTEd April 5, 1996)

\begin{abstract}
A thorough sequence analysis of the various members of the eukaryotic protein serine/threonine phosphatase $2 \mathrm{C}$ (PP2C) family revealed the conservation of 11 motifs. These motifs could be identified in numerous other sequences, including fungal adenylate cyclases that are predicted to contain a functionally active PP2C domain, and a family of prokaryotic serine/ threonine phosphatases including SpolIE. Phylogenetic analysis of all the proteins indicates a widespread sequence family for which a considerable number of isoenzymes can be inferred.
\end{abstract}

Keywords: alignment; bacterial serine/threonine phosphatases; homology search; PP2C; SpoIIE.

Whereas the basic metabolic pathways and many other essential cellular processes are clearly identified in all three kingdoms (eubacteria, eukaryotes, and archaebacteria), the evolution of many eukaryotic regulatory processes remains to be elucidated. Protein phosphatases mediate major signaling steps, but so far, only a few bacterial or archaebacterial relatives have been reported. For example, a protein tyrosine phosphatase has been identified in the cyanobacterium Nostoc commune (Potts et al., 1993) and a serine/threonine phosphatase was found in the archaebacterium Sulfolobus solfataricus (Leng et al., 1995). The Escherichia coli ApaH gene encoding a diadenosine tetraphosphatase, a pleiotropic regulator, was shown to be related to a family of serine/threonine phosphatases (Koonin, 1993).

Two distinct serine/threonine phosphatase sequence families exist (Klumpp et al., 1994): PP2C and PPP (Cohen, 1994). The latter comprise PP1, PP2A, and PP2B, which have distinct biochemical properties (Cohen, 1989).

The antagonistic roles of PPPs with respect to protein kinasetriggered regulation pathways are well established (for review see Cohen, 1992), but experiments aiming at the determination of the cellular functions for PP2C family members have started only very recently (Leung et al., 1994; Meyer et al., 1994; Rob-

Reprint requests to: Peer Bork, EMBL, Meyerhofstr.1, 69117 Heidelberg, Germany; e-mail: bork@embl-heidelberg.de.

Abbreviations: LRR, leucine-rich repeat; PP2C, protein phosphatase II C; PPP, phosphoprotein phosphatase. inson et al., 1994; Shiozaki \& Russell, 1995). Nevertheless, there is a detailed biochemical knowledge showing the requirement for $\mathrm{Mg}^{2+}, \mathrm{Mn}^{2+}$-binding in vitro, and the stimulation by $\mathrm{Ca}^{2+}$ ions (Cohen, 1989). Recently, numerous PP2C-like genes from various species have been cloned and characterized. Here we summarize all the data on the $\mathrm{PP} 2 \mathrm{C}$ family and characterize conserved sequence features of the family that have enabled us to identify new members and to establish a link to prokaryotic phosphatases.

Iterative collection of the PP2C family members: An alignment of the PP2C members annotated in PROSITE (Bairoch \& Bucher, 1994; entry PS01032) was the starting point for iterative sequence homology searches using several pattern search methods (for details of the strategy see Bork \& Gibson, 1996). After each iteration, newly detected sequences were added to the alignment using CLUSTALW (Thompson et al., 1994). A total of 11 conserved motifs were identified that mostly seem to correspond to structural elements and exposed functional residues that are scattered along the sequence (Fig. 1). Mitochondrial pyruvate lipoamide phosphatase was included into the initial alignment because it has been shown to belong to the family (Lawson et al., 1993) and as it has been annotated in PROSITE. Whereas the first iteration only collected members that are already known to belong to the family, but that are too divergent or too recently sequenced to be annotated in PROSITE, subsequent searches revealed the presence of all motifs in a hypothetical yeast protein (YCW9; e.g., 7.4 standard deviations above the expected using profile searches; Gribskov et al., 1987). Another yeast protein was identified as a putative phosphatase by motif searches (MoST; Tatusov et al., 1994) using the conserved motifs 2 and 11 (YHN6 in Fig. 1; in both cases, the stringent threshold $r=$ 0.01 was used, whereby $r$ is the ratio of observed versus expected occurrences; Tatusov et al., 1994).

Proposed PP2C activity in fungal adenylate cyclases: Blastp database searches (Altschul et al., 1990) with members of the eukaryotic PP2C family significantly detect (probability of chance matches $p<10^{-15}$ ) the presence of a complete PP2C domain in fungal cyclases; a similarity that has already been noted (Tamura et al., 1989; Robinson et al., 1994). Remarkably, the 
predicted PP2C domain covers exactly the area between the leucine-rich repeats and the catalytic domain (Fig. 2). Mutation experiments in this domain show that the cyclase activity is not dependent on the PP2C domain (Suzuki et al., 1990; Feger et al., 1991). However, the domain seems to be $\mathrm{Mg}^{2+}$-dependent (Lacombe \& Eberentz-Lhomme, 1983), is required for $\mathrm{Mg}^{2+}$-dependent Ras-binding (Suzuki et al., 1990), and negatively regulates the catalytic domain (Feger et al., 1991). These are all features in accordance with a PP2C-like activity. Furthermore, several membrane-bound guanylate cyclases contain a protein kinase (Fig. 2) that precedes the catalytic domain (Singh et al., 1988) and that is supposed to regulate the catalytic activity (Koller et al., 1992; Jewett et al., 1993; Rudner et al., 1995). Because phosphorylation is a key regulation mechanism for cyclases, and because Ser/Thr-phosphatases have been implicated in cyclase activity (Chern et al., 1995), a catalytically active phosphatase domain is very likely. This is supported by the alignment (Fig. 1), which indicates that most of the residues conserved in eukaryotic PP2Cs are also present in cyclases.

To our surprise, we found a PP2C domain closely related to those in cyclases in a Caenorhabditis elegans protein (YR71 in Fig. 1) that does not contain a cyclase domain, but in which
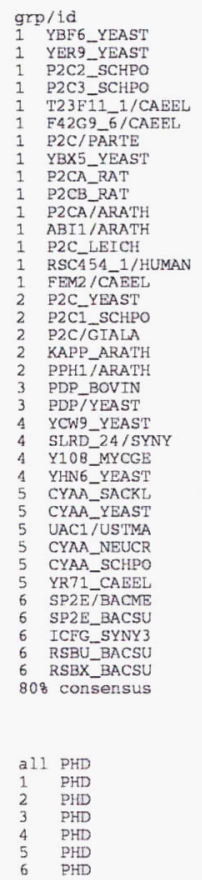

motif $5 b$

SEKSRIVAADGFVEMD - SEKSRIVAADGFVEMD AEKARICAAGGFVDFC- VETRRI IAAGGGQIEDD EERSRI ERAGGFVSD -MEKERI QNAGGSVMIQ -DELIRIQQAGGRVIYWD GERQRI ENCAGRVENN -DEKARIEALGGFVSHMDCNESRRVTQLLGGLMVQN LEIDRI KSLGGTVIFCPEVKRVKEAGGWIVNG--.--RICGDIAVSRAFGDIREKT-<32>
- VERLKLEHPKNEAKSVVKQD-RLLGLLMPFRAGDVKFKW-<37>VRRIRKEHP--GEPNVIRNG-RILGSLQPSRAFGDYRYKI-<34> -RERHRL SIDPSRLDPDAFGET -YNQLVAMNADEKLLLSYS EEYERTRTSGGYVIN - EEYERIRISGGYVNN-- VERSRIRNAGGWVSRN -DEYSRIREAHGFVDEEN---

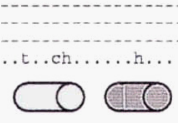

HHHHHHHh. LLeeee. HHHHHHHHTLLEEEQL
HHHHHHHHHLLL. EEEE HHHHHH. LLLLLLL.
LLL. eeee. ....L.L

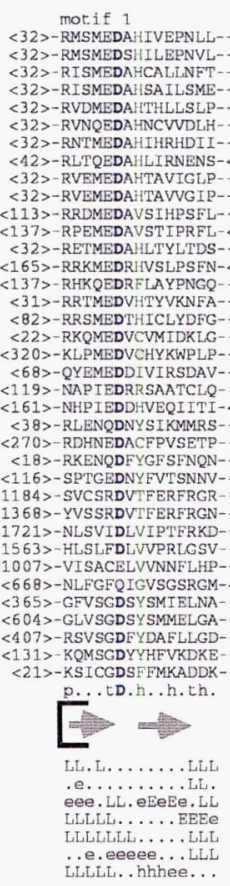

motif

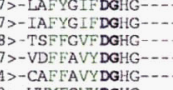

motif 3
motif 4 GAKVAEYCGNKIVEILQ GDKVAKWCGSNLPQI LEK GSKVSQYSGINLHKKVV
GTEVSKFT SAKLPDFLK
GREVAOFVEKHEVDELL GDDCKFLSGGRHHRDC GSRVANYCSTHLLEHIT SSQVANYCRERMHLALA -GVDAARYAAVHVHTINAAR GHECSQYAAGHLWETWLE GQEAARIAGDNLHKYYLL GQAARIAGDNLHRYLLL -GSSSVKFELREEL YKECV -GAQLSQLLADKLCSSLDP
-GQECGETASQWVIEHLPV
-GYKGGKIASNLVGKLFLS

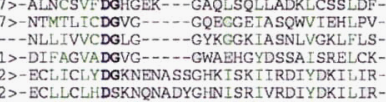

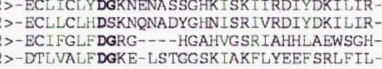
-SSLYCVLDSDI-SAGKNNRVLKFVYDNLASC LAH - NSYMSSSICRFMTSYLLE--

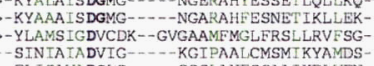
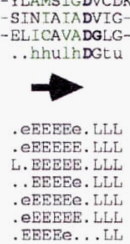
GGSLANESSAAIKDLVI

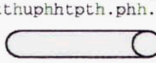

L. . КНHНHНHНHНHНH h THFHHFHHHHHHHFHH

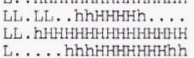

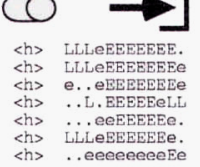
RVNGNLALSRAIGD RVNGNLALSRAL GDFAEKN RVNGGLNLSRAFGDHAY RVGGVLALSRAFSDEQ RVNGSLAVSRALGDYD RVEGVLAMSRA IGDNYLKY RVDGSAMSRST GDRYLKP RVNGTLAVSRAIGDVEOKLPWRVNGVLNLTRA GDVPGR RVNGMLAVTRSLGDKFFDSRILGSLQPSRAFGDYRYK PRSGALT TQAVGLGPSK -RGSKYILNTPRDADEYSFQGKLDGVVDVSRAVGFFDLLP GINDVLNVSRAFGYTELLLP - RINGVIGSSRQIGHFSTFY DVVKVVASNLPT GI INEF SEGIKHRLKST GPAVGM
-KDNTFYDLEAKGLVLGI

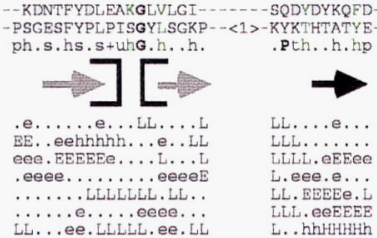

motif 8

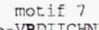

VPDILEHSL

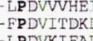

- LPDVKIEA

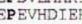

EPEVYEIT

-DPEVTVTTDR
DPEVTAVKR
-

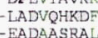

\begin{tabular}{l} 
HPETTETRIV \\
-TPDSVGVTA \\
- EPYTSEPLR \\
\hline
\end{tabular}

EPDIFQVPLI

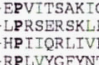

-RPLVYGFYNT--

2 >-KKDIIIILATD
$4>-$ SPDISETVLS
-

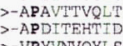

APDITEHTID
-VPYVNQYLS
-PTHSYRNIQ-

- LPTHSYRNI
EVDVVNEQMK
- DVEVVSEQL

SQDYDYKQFD -

YDEDEFVT LACDG TWD

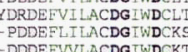

PEDEF TVVACDGIWINSM

PQDKFTI MCCDQVEFETL

EDDQFI TLACDG IWDVVM

DEDECLI LASDG LWDVV

KEDDCLI ILASDGVWDVM

GSEDYLLLACDGEEDVV

SEDKFLITACDGLIWDVID

-NGHDEFFI I IACDGLWDVVS

SSKDVFAVIASDGLWDVVV

-SDVEFI I LA.SDG LWDYMK

ENTKFMVMGSDGLFE

-TDC LFLLCSDGFCDYNR

NIATDDIELFL KDNAARTND
- YSDEMLI IATHKL WEYLD - KADEMLI IVATHKLWEYM

- DKDETVLITASKEL WEHLR

BLNEFI LANQEFWSVLS
LNEQIEGLIVGNNMI WNML -ABDLLIMMSDGVF BGPK
-AGDLLIMMSDG F FGPK
-

QHL EKGDMTVLFSDGVT BCRT -RGSKFI IHTDGLNVP--
psch11IssDG lachhp

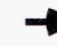

LLL. EEEEeLLLLHHHHH LLL. EEEEE. LLL ... LL WLEEEEEL L. WHHhh. LLL. EEEEe, hhHHHh. motif 9

SQECVDLVHYG

SQDCVDLVHL
SQQVVEFVRR
SQQVIEFVR

SQEVVDDFVRKLL

HQELLKQVNSTI

-NEELCDFVRSR

NETACGVARMCL

PNEEVVAYVKQQR

ERDLYQLVEAFAN

DQEAVDEVRNEVS

-PREAAVRLVEFFALKRL
-

-DQEVVDLITSTVN- $-<3>-<$ - LKKATPQFVAEETIKF-

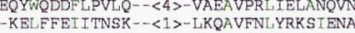

SQKFVDNVVSLSK--<4>-PSVFAQEI SKLTGKNY
-YETVCDISRENKS--<1>-PMSAAEKMKDYYISYG

VDTVCDIARENS

- PELIVDVIARTQRRS

-IDDLNSTFHANRS
HVENYEMWMKRTIC

HVENHDLWMKRKMY

-PTKEEFGRQRLM
ENGFLERPDLQKLI

-pphhthhpt.ht

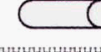

hHHHHHHHHHHH

LThHHHHFHHH

HHHHHHHHHHH

hithhhhhhHh. Li

. . HसHHHHHH
1>-PMIAAQKLRDEAISYG
1>-LMKASQKLRDLATAYG

1)- PLLA STKLRDYATAYYG

-PIVUAKKIQDQLQSYD

6>-PQEIADLIMEEVIRTR -

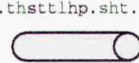

ПHHHHHHHHHHHWhin hinHHHHHHHAHhh. L hihhHHHHHHHHHHLLLL HHHHHHHHHHHHHYh.
AQENVKNI YDSLLKLLQ motif 5a 5 -GGNSKAMSFDHKPTLL---DGNAKALSYDHKPTLA
KGTAEPLSFDHK PNND KGIAKPLSADHKRPSNEVGEARPLSEDHKPSHE NNTNHDMSVDHKRPDNP SNGIKTMSEDHKPQHI NGQVCESTQDHKPCN NGVAIPLSVDHRPDRP
GKTALPSVDKRDRE DGVCVPLTEDHKPNNEQGQVVKLLMEPHR PERQ -NGNSIRLTYDHKASDT DGKAIRLSYDHKGSDA GGRY IQMTEDHRVVSL--SGQI EELTDYHRPYGSSRAA DIAHALTTTHHINS ENQAKLVTKDHNL DSKLVFQTKFQTVGEN NNGDYQTLTKQHLPTKR NGGTAHLI SNKHEPFDR ANGSFKMLTKKKHDPADP

-

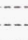

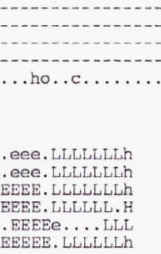

LLL. EEEEE..... LLE

.

motif 11

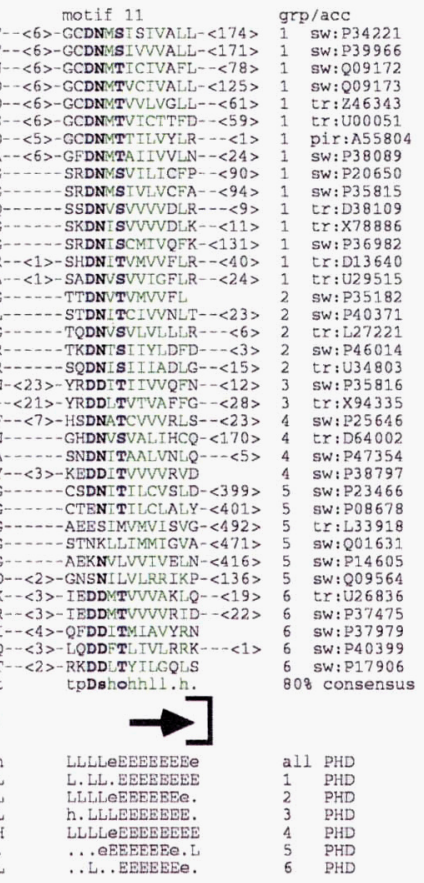




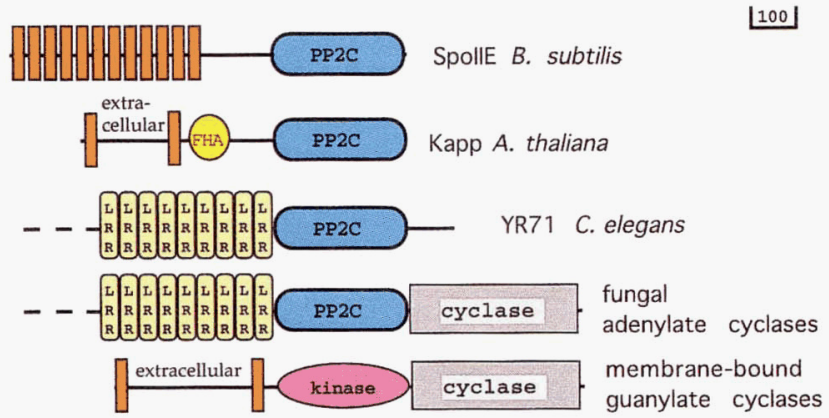

Fig. 2. PP2C as module in diverse proteins. Only PP2Cs are shown for which neighboring domains with a distinct function are known. Vertical orange bars denote transmembrane regions. Only the C-terminus of the cyclases, including some of the LRRs, are displayed. The location of PP2C in adenylate cyclases is striking compared to the functional protein kinase domain in several guanylate cyclases (the catalytic domains of adenylate and guanylate cyclases are homologous).

LRRs also precede the PP2C domain. Thus, this subfamily of $\mathrm{PP} 2 \mathrm{Cs}$, which is most characterized by a modification of motif 8 (e.g., the lack of an otherwise conserved aspartate-glycine dipeptide; Fig. 1), appears to be more widespread than in fungal adenylate cyclases.

Identification of prokaryotic relatives with serine/threonine phosphatase activity: Two prokaryotic proteins from $\mathrm{Myco}$ plasma genitalium and Synechocystis $s p$. have a relationship to the group of characterized eukaryotic PP2Cs (Fig. 1) that is detectable by Blastp $\left(p<10^{-9}\right)$. Both putative gene products have been obtained by genome sequencing projects (Fraser et al., 1995; Kaneko et al., 1995). The respective gene in $M$. genitalium succeeds a gene coding for a putative protein kinase (Fraser et al., 1995). Because PP2Cs have not been and protein kinases have very rarely been observed in prokaryotes, horizontal gene transfer would be a reasonable working hypothesis. We were able to identify, however, a more remote group of bacterial PP2Cs, including SpoIIE from Bacillus subtilis (running MoST on motifs 4,8 , and 11 with the threshold $r=0.01$ ). The alignment (Fig. 1) shows that the prokaryotic phosphatases share all but two motifs $(5 \mathrm{a}, 5 \mathrm{~b})$ with the eukaryotic PP2Cs.

In support of our finding, SpoIIE has been characterized recently as a serine/threonine protein phosphatase involved in asymmetric cell division and sporulation (Duncan et al., 1995). Several other Bacillus proteins, as well as an ORF from Synechocystis sp., indicate a more widespread occurrence of this type of phosphatase in eubacteria. This group of prokaryotic serine/ threonine phosphatases differs from the eukaryotic ones in some of the conserved motifs (Fig. 1). Because SpoIIE is involved in fundamental processes of bacterial cell division (Arigoni et al., 1995; Duncan et al., 1995), the roots of the PP2C family indeed seem to lie in the eubacterial kingdom, although additional prokaryotic phosphatases supporting this rooting need to be identified. Although $\mathrm{Mn}^{2+}$-binding has been demonstrated for SpoIIE (Duncan et al., 1995), we are not aware of data about the $\mathrm{Mg}^{2+}$-dependency of the prokaryotic members; $\mathrm{Mg}^{2+}$-binding might be one reason for the presence of additional conserved motifs within the eukaryotic PP2C members compared to the prokaryotic ones (Fig. 1).

Common features of the enlarged PP2C superfamily: In spite of the high divergence of the PP2C superfamily, the signature motifs identified leave little doubt about the enlarged PP2C superfamily. The similarities are strongly supported by secondary structure predictions that have been conducted separately for each subfamily (consensus shown in Fig. 1).

The consecutive $\beta$-strands separated by $\alpha$-helices suggest a $\beta+\alpha$ structural type in which antiparallel $\beta$-sheets are surrounded by $\alpha$-helices. Interestingly, the secondary structure ar-

Fig. 1 ( facing page). Multiple alignment of conserved regions of the PP2C superfamily showing 11 sequence motifs. It was constructed using CLUSTALW (Thompson et al., 1994) by merging six pre-aligned subfamilies based on phylogenetic analysis (Fig. 3). Only very few regions were modified, as suggested by the secondary structure predictions (Rost et al., 1994) conducted independently for each subfamily. First and last columns show subfamily number (1-6) and SWISS-PROT identifier and database accession number, respectively. Intervening columns give the alignment as 11 motifs numbered along the top, with gaps indicated by hyphens, and numbers in angle brackets to indicate residues that are not displayed. Organism codes: ARATH, Arabidopsis thaliana; BACME, Bacillus megaterium; BACSU, Bacillus subtilis; BOVIN, Bos taurus; CAEEL, Caenorhabditis elegans; GIALA, Giardia lamblia; HUMAN, Homo sapiens; LEICH, Leishmania chagasi; MYCGE, Mycoplasma genitalium; NEUCR, Neurospora crassa; PARTE, Paramecium tetraurelia; RAT, Rattus norvegicus; SACKL, Saccharomyces kluyveri; SCHPO, Schizosaccharomyces pombe; SYNY,SYNY3, Synechocystis sp.; USTMA, Ustilago maydis; YEAST, Saccharomyces cerevisiae. Functional assignment codes: $\mathrm{P} 2 \mathrm{CA} \_$RAT, P2CB_RAT, P2CA/ARATH, P2C_LEICH, protein phosphatases 2C and isoforms; P2C_YEAST, P2C1_SCHPO, P2C2_SCHPO, P2C3_SCHPO, P2C/GIALA, YBF6_YEAST, YER9_YEAST, YBX5_YEAST, putative protein phosphatase 2C homologues; F42G9_6/CAEEL, P2C/PARTE, KAPP_ARATH, ABI1/ ARATH, protein phosphatases; PPH1/ARATH, T23F11_1/CAEEL, putative protein phosphatase homologues; PDP_BOVIN, $\mathrm{PDP} / \mathrm{YEAST}$, pyruvate dehydrogenase phosphatase, catalytic subunit; SP2E_BACSU, SP2E/BACME, stage II sporulation protein E; ICFG_SYNY3, ICFG protein; RSBU_BACSU, Sigma factor SIBG regulation protein RSBU; RSBX_BACSU, Sigma-B negative effector; CYAA_SACKL, CYAA_YEAST, CYAA_NEUCR, CYAA_SCHPO, UAC1/USTMA, adenylate cyclases; YCW9_YEAST, Y108_MYCGE, YHN6_YEAST, YR71_CAEEL, SLRD_24/SYNY, RSC454_1/HUMAN, FEM2/CAEEL, hypothetical proteins and/or unassigned function. Residues conserved between subfamilies are shown in bold; those with properties conserved in $90 \%$ of all sequences are colored: green, hydrophobic; blue, similarly charged or polar. The consensus line immediately beneath the alignment indicates residues or amino acid properties conserved in $80 \%$ of all sequences: h, hydrophobic; a, aromatic; 1, aliphatic; o, S/T; p, polar; c, charged; +, positive; -, negative; s, small; u, tiny; t, turn-like (polar or tiny). Consensus PHD secondary structure predictions: $\mathrm{H} / \mathrm{h}$, helix; E/e, strand; L/dot, loop with $>80 \% / 70 \%$ expected accuracy, respectively (Rost et al., 1994), are then shown for the entire alignment (all) and for the six numbered subfamilies. An additional helix lying between motifs 3 and 4 is indicated in angle brackets, but not shown in the alignment. Assuming two $\beta$-strands N-terminal of motif 2 , and a helix-strand arrangement in motif 6 , the unit $\beta \beta \beta \alpha \alpha \beta$ (in brackets in the graphical interpretation of the predictions) seems triplicated (arrows, $\beta$-strands; cylinders, $\alpha$-helices; grey, not verified by the automatic prediction). 
rangement $\beta \beta \beta \alpha \alpha \beta$ seems to occur three times successively (Fig. 1), and might indicate a triplication of this unit. Assuming an antiparallel $\beta$-sheet, all conserved residues located in the predicted $\beta$-hairpins would be on one side of the sheet, probably forming the active site.

Provided that all proteins identified in this study are indeed protein phosphatases (this has been shown experimentally for divergent members such as SpolIE; see Fig. 3), polar and charged residues conserved in all the divergent subfamilies should be crucial for catalytic activity. Only two residues, an aspartate in motif 2 and a glycine in motif 5 , remain invariant. Thus, the motif conservation within the PP2C family has to be reevaluated. We predict that the most conserved region in the classical eukaryotic PP2Cs (between motif 5 and 6 in Fig. 1) that is absent in the bacteria reflects more substrate specificity or
$\mathrm{Mg}^{2+} / \mathrm{Ca}^{2+}$-binding than a catalytic requirement. The conserved polar and charged residues in motifs $1,2,5$, and 11 seem essential for the phosphatase activity. Most of the other conserved polar residues are absent from one or another subfamily, pointing to different regulation or substrates.

The variety of substrates can be estimated by the number of paralogues that occur in a single organism and also by the arrangement of the sequenced members in a phylogenetic tree (Fig. 3). As in many branches, the grouping of species is different from what one would expect; the existence of many more PP2C-like paralogues can be assumed. The public databases searched contained about $80 \%$ of all yeast proteins. Thus, extrapolating from the eight yeast $\mathrm{PP} 2 \mathrm{Cs}$ we have recognized (Figs. 1, 3), there might be at total of about 10 paralogues in yeast, and we cannot exclude the presence of additional remote

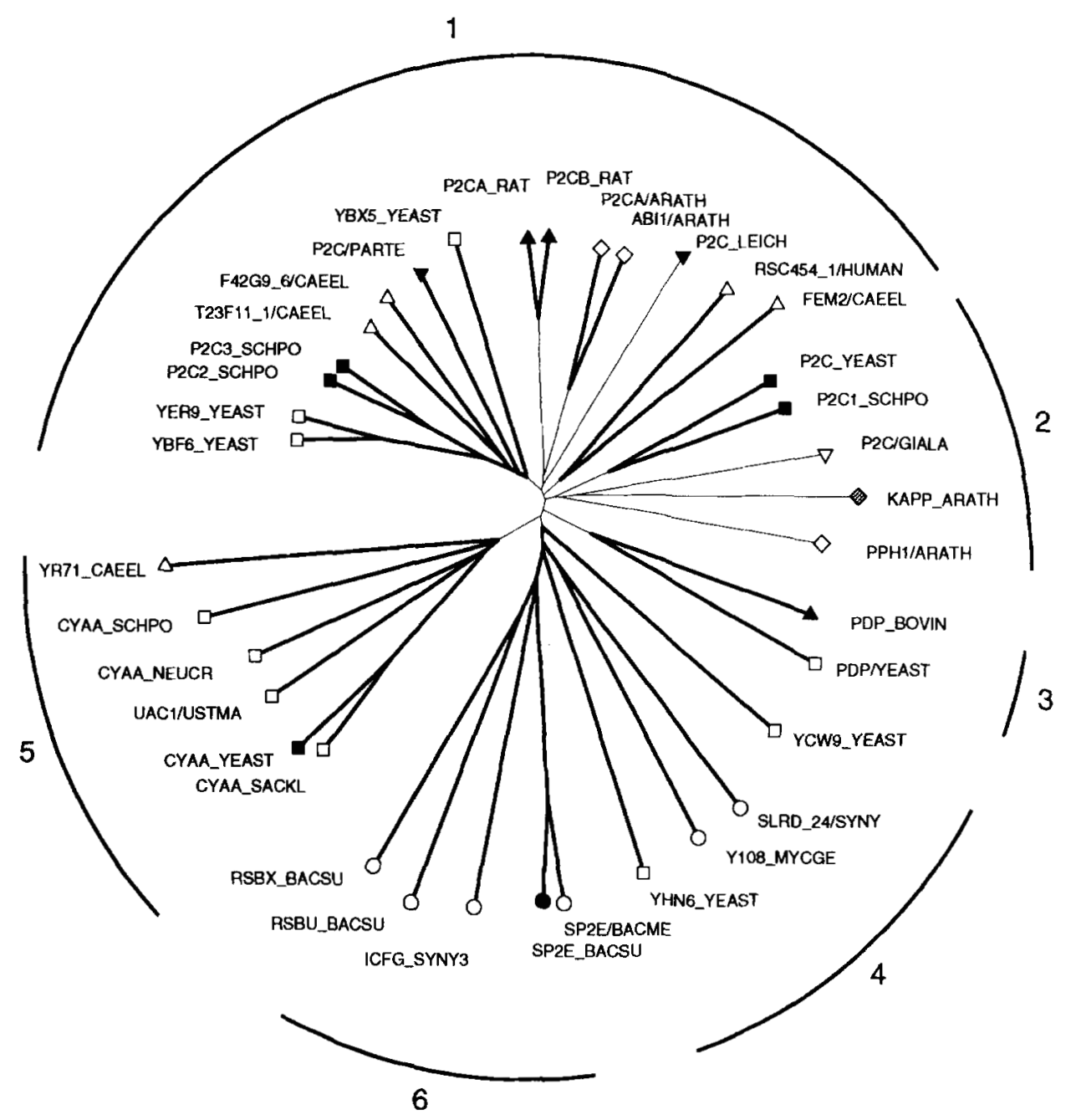

Fig. 3. Unrooted phylogenetic tree of selected PP2C members. The neighbor-joining method in CLUSTALW (Thompson et al., 1994) was used with bootstrapping to construct the tree based on the conserved sequence motifs alone. Thick lines indicate subtrees stable in at least 500/1,000 bootstraps. Sequences are labeled with their SWISS-PROT identifiers and symbols denoting major organism groups: circle, bacteria; square, fungi; diamond, higher plants; downward triangle, protozoa; upward triangle, animals. Experimentally determined phosphatase activity is shown by a filled symbol (gray or black), with black reserved for verified $\mathrm{Mg}^{2+} / \mathrm{Mn}^{2+}$-binding. The location of the experimentally verified phosphatases in the tree suggests that most, if not all, members are catalytically active. Based on the tree, six subfamilies numbered around the edge and shown in Figure 1 have been defined. 
members that might have escaped our attention. In animals, regulatory cascades are usually much more complex and the number of paralogues therein will probably be much higher.

The 11 motifs identified should therefore prove useful in the identification of additional members remaining to be sequenced. The alignment in Figure 1 should guide the characterization of specific features of the identified subfamilies when more functional information can be attached to particular members.

\section{References}

Altschul SF, Gish W, Miller W, Myers EW, Lipman DJ. 1990. Basic local alignment search tool. J Mol Biol 215:403-410.

Arigoni F, Pogliano K, Webb CD, Stragier P, Losick R. 1995. Localization of protein implicated in establishment of cell type to sites of asymmetric division. Science 270:637-40.

Bairoch A, Bucher P. 1994. PROSITE: Recent developments. Nucleic Acids Res 22:3583-3589.

Bork P, Gibson T. 1996. Applying motif and profile searches. Methods Enzymol 266:162-184.

Chern Y, Chiou JY, Lai HL, Tsai MH. 1995. Regulation of adenylyl cyclase type VI activity during desensitization of the A2a adenosine receptor-mediated cyclic AMP response: Role for protein phosphatase $2 \mathrm{~A}$. Mol Pharmacol 48:1-8.

Cohen P. 1989. The structure and regulation of protein phosphatases. Annu Rev Biochem 58:453-508.

Cohen P. 1992. Signal integration at the level of protein kinases, protein phosphatases and their substrates. Trends Biochem Sci 17:408-413.

Cohen PTW. 1994. Nomenclature and chromosomal localization of human protein serine/threonine phosphatase genes. Adv Protein Phosphat 8: 371-376.

Duncan L, Alper S, Arigoni F, Losick R, Stragier P. 1995. Activation of cellspecific transcription by a serine phosphatase at the site of asymmetric division. Science 270:641-644.

Feger G, De-Vendittis E, Vitelli A, Masturzo P, Zahn R, Verrotti AC et al. 1991. Identification of regulatory residues of the yeast adenylyl cyclase. EMBO J 10:349-359.

Fraser CM, Gocayne JD, White O, Adams MD, Clayton RA. 1995. The minimal gene complement of Mycoplasma genitalium. Science 270:397-403

Gribskov M, McLachlan AD, Eisenberg D. 1987. Profile analysis: Detection of distantly related proteins. Proc Natl Acad Sci USA 84:4355-4358.

Jewett JR, Koller KJ, Goeddel DV, Lowe DG. 1993. Hormonal induction of low affinity receptor guanylyl cyclase. EMBO J 12:769-777.

Kaneko T, Tanaka A, Sato S, Kotani H, Suzuki T, Miyajima N et al. 1995. Sequence analysis of the genome of the unicellular cyanobacterium Synechocystis sp. strain PCC6803. I. Sequence features in the $1 \mathrm{Mb}$ region map position: $64 \%-92 \%$ of the genome. DNA Res 2:153-166.

Klumpp S, Hanke C, Donella-Deana A, Beyer A, Kellner R, Pinna LA et al. 1994. A membrane-bound protein phosphatase type 2C from Paramecium tetraurelia. J Biol Chem 269:32774-32780.
Koller KJ, de-Sauvage FJ, Lowe DG, Goeddel DV, 1992. Conservation of the kinaselike regulatory domain is essential for activation of the natriuretic peptide receptor guanylyl cyclases. Mol Cell Biol 12:2581-2590.

Koonin EV. 1993. Bacterial and bacteriophage protein phosphatases. Mol Microbiol 8:785-786.

Lacombe ML, Eberentz-Lhomme C. 1983. Protoporphyrin IX activates the $\mathrm{Mg}$ dependent guanylate cyclase from rat liver plasma membranes. Biochem Biophys Res Commun 116:47-53.

Lawson JE, Niu XD, Browning KS, Trong HL, Yan J, Reed LJ. 1993. Molecular cloning and expression of the catalytic subunit of bovine pyruvate dehydrogenase phosphatase and sequence similarity with protein phosphatase 2C. Biochemistry 32:8987-8993.

Leng J, Cameron AJM, Buckel S, Kennelly PJ. 1995. Isolation and clon ing of a protein-serine/threonine phosphatase from an archaeon. $J$ Bac teriol 177:6510-6517.

Leung J, Bouvier-Durand M, Morris PC, Guerrier D, Chefdor F, Giraudat J. 1994. Arabidopsis ABA response gene ABI1: Features of a calciummodulated protein phosphatase. Science 264:1448-1452.

Meyer K, Leube MP, Grill E. 1994. A protein phosphatase 2C involved in ABA signal transduction in Arabidopsis thaliana. Science 264:1452-1455.

Potts M, Sun H, Mockaitis K, Kennelly PJ, Reed D, Tonks NK. 1993 . A protein-tyrosine/serine phosphatase encoded by the genome of the cyanobacterium Nostoc commune UTEX 584. J Biol Chem 268:7632-7635.

Robinson MK, van-Zyl WH, Phizicky EM, Broach JR. 1994. TPD1 of Sac charomyces cerevisiae encodes a protein phosphatase $2 \mathrm{C}$-like activity implicated in tRNA splicing and cell separation. Mol Cell Biol 14 3634-3645.

Rost B, Sander C, Schneider R. 1994. PHD-An automatic mailserver for protein secondary structure prediction. Comput Appl Biosci 10:53-60.

Rudner XL, Mandal KK, de-Sauvage FJ, Kindman LA, Almenoff JS. 1995. Regulation of cell signaling by the cytoplasmic domains of the heat-stable enterotoxin receptor: Identification of autoinhibitory and activating motifs. Proc Natl Acad Sci USA 92:5169-5173.

Shiozaki K, Russell P. 1995. Counteractive roles of protein phosphatase 2C (PP2C) and a MAP kinase kinase homolog in the osmoregulation of fission yeast. EMBO J 14:492-502.

Singh S, Lowe DG, Thorpe DS, Rodriguez H, Kuang WJ, Dangott LJ et al 1988. Membrane guanylate cyclase is a cell-surface receptor with homology to protein kinases. Nature 334:708-712.

Suzuki N, Choe HR, Nishida Y, Yamawaki-Kataoka Y, Ohnishi S, Tamaoki $T$ et al. 1990. Leucine-rich repeats and carboxyl terminus are required for interaction of yeast adenylate cyclase with RAS proteins. Proc Natl Acad Sci USA 87:8711-8715.

Tamura S, Lynch KR, Larner J, Fox J, Yasui A, Kikuchi K et al. 1989. Molecular cloning of rat type $2 \mathrm{C}$ (IA) protein phosphatase mRNA. Proc Nat Acad Sci USA 86:1796-1800.

Tatusov RL, Altschul SF, Koonin EV. 1994. Detection of conserved segments in proteins: Iterative scanning of sequence databases with alignment blocks. Proc Natl Acad Sci USA 91:12091-12095.

Thompson JD, Higgins DG, Gibson TJ. 1994. CLUSTAL W: Improving the sensitivity of progressive multiple sequence alignment through sequence weighting, position-specific gap penalties and weight matrix choice. $\mathrm{Nu}$ cleic Acids Res 22:4673-4680. 